\title{
GSK3 $\beta$ is a key regulator of the ROS-dependent necrotic death induced by the quinone DMNQ
}

\author{
Sonia Ciotti', Luca Iuliano ${ }^{1}$, Sebastiano Cefalù ${ }^{1}$, Marina Comelli', Irene Mavelli', Eros Di Giorgio and Claudio Brancolini ${ }^{1}$
}

\begin{abstract}
Signaling pathways controlling necrosis are still mysterious and debated. We applied a shRNA-based viability screen to identify critical elements of the necrotic response. We took advantage from a small molecule (G5) that makes covalent adducts with free thiols by Michael addition and elicits multiple stresses. In cells resistant to apoptosis, G5 triggers necrosis through the induction of protein unfolding, glutathione depletion, ER stress, proteasomal impairments, and cytoskeletal stress. The kinase GSK3 $\beta$ was isolated among the top hits of the screening. Using the quinone DMNQ, a ROS generator, we demonstrate that GSK3 $\beta$ is involved in the regulation of ROS-dependent necrosis. Our results have been validated using siRNA and by knocking-out GSK3 $\beta$ with the CRISPR/Cas9 technology. In response to DMNQ GSK3 $\beta$ is activated by serine 9 dephosphorylation, concomitantly to Akt inactivation. During the quinone-induced pronecrotic stress, GSK3 $\beta$ gradually accumulates into the nucleus, before the collapse of the mitochondrial membrane potential. Accumulation of ROS in response to DMNQ is impaired by the absence of GSK3 $\beta$. We provide evidence that the activities of the obligatory two-electrons reducing flavoenzymes, NQO1 (NAD(P)H quinone dehydrogenase 1) and NQO2 are required to suppress DMNQ-induced necrosis. In the absence of GSK3 $\beta$ the expression of NQO1 and NQO2 is dramatically increased, possibly because of an increased transcriptional activity of NRF2. In summary, GSK3 $\beta$ by blunting the anti-oxidant response and particularly NQO1 and NQO2 expression, favors the appearance of necrosis in response to ROS, as generated by the quinone DMNQ.
\end{abstract}

\section{Introduction}

In multicellular organisms cell death processes regulate organogenesis and tissue homeostasis. These forms of cellular demise have been generally considered as programmed cell death ${ }^{1,2}$. Noxious insults can also trigger cell death, as the result of an unmanageable damage. These varieties of cell elimination belong to the group of the accidental cell death ${ }^{3,4}$. Programmed and accidental cell deaths can be accomplished by the engagement of distinct signaling pathways, which activate both common and distinct molecular machineries devoted to cells elimination $^{1,5-7}$. Apoptosis is a cell autonomous and evolutionary conserved genetic program, evolved to finalize a harmonious cellular disassembling.

Correspondence: Claudio Brancolini (claudio.brancolini@uniud.it)

'Department of Medicine, Università degli Studi di Udine. P.le Kolbe 4, 33100 Udine, Italy

Edited by A. Finazzi-Agrò
In cells deficient for apoptosis cell death can still occur through alternative mechanisms. Moreover, certain stimuli can directly engage alternative death pathways such as ferroptosis or necroptosis ${ }^{6-9}$. Necrosis can also be triggered by noxious insults and apoptosis and necrosis can, in some conditions, co-exist. Despite the mechanisms controlling cell death by apoptosis are well-known, the existence of specific molecular players regulating necrosis is still debated ${ }^{8}$.

G5 is a non-selective isopeptidases inhibitor that can react with cellular thiols, thus eliciting multiple cellular stresses $^{10-15}$. G5 belongs to a family of compounds that have been synthetized and investigated for the ability to commend accidental death in cancer cells, with therapeutic perspectives ${ }^{16-22}$. Protein misfolding, ER-stress, deubiquitinases inhibition and accumulation of polyubiquitylated proteins, glutathione depletion, alterations of the actin cytoskeleton and of the cell adhesion mark the cellular response to G5. In cells resistant to apoptosis this 
plethora of stresses can result in a necrotic death, which is distinguishable from necroptosis ${ }^{11,13,14}$. However, few additional data are available about the signaling networks transducing this peculiar form of necrosis.

G5, due to its pleiotropic effects, represents an ideal compound to identify genes controlling different stress signaling pathways that ultimately conduct to a necrotic death. For this reason, we conducted a functional shRNAbased screening aimed to identify genes that can influence cell survival in response to this compound. We used as a model the glioblastoma cell line U87MG, which activates necrosis when treated with high doses of $\mathrm{G} 5^{12,14}$.

\section{Results}

shRNA screen to identify elements of the necrotic death induced by the proteotoxic stressor $\mathbf{G 5}$

To identify genes controlling G5-induced necrosis, we conducted a shRNA-based survival screen, using Cellecta's Lentiviral shRNA Library Module 1. This module targets 5046 signaling pathway associated genes and consists of 27.500 shRNAs. For every target are present from 5 to 6 different shRNAs. U87MG cells were chosen as cellular model, because of their propensity to die by necrosis in response to $\mathrm{G} 5^{12}$. The screen was based on the hypothesis that U87MG cells expressing a shRNA, targeting a gene necessary for the G5-induced cell death, would show a survival advantage and would be overrepresented after sequencing.

The infection and the selection scheme is described in Fig. 1a. Briefly, after 2 days of recovery from infections, cells were treated with puromycin and, after 3 days of selection, G5 was added for $60 \mathrm{~h}$. Genomic DNA was extracted from the surviving cells and the abundance of every integrated shRNA-specific barcode was amplified by PCR with vector-specific primers and identified using high-throughput (HT) sequencing. The deconvolution and normalization of the reads for each barcode, respect to control shRNAs (against the Luciferase), has revealed the identity of the most enriched shRNAs. The relevant "hits" were defined when at least three different shRNAs were enriched in comparison to the median value of the control shRNAs targeting the luciferase (1541 reads) or the median value for all shRNAs (1490 reads). In order to isolate genes that could play key functions in transducing the necrotic signal, we imposed that the second shRNAs was to be enriched $>3$ fold compared to the median value. In this manner we selected 371 genes (Fig. $1 \mathrm{~b}$ and Table S1). Among the top target genes we identified: RNASEL, POU5F1, GSK3B, CAPN1, and DUSP10. We focused the attention on glycogen synthase kinase-3 $\beta$ (GSK3 $\beta$ ) for two main reasons. First GSK3 $\beta$ can be activated under specific stress-conditions and it is involved in the regulation of cell death pathways in different cellular contexts $^{23-27}$. Second, among other represented hits interacting proteins, regulators and substrates of GSK3 $\beta$ were found. These include Calpain- 1 (CAPN1) ${ }^{28}$, the protein phosphatase-1 (PPP1) ${ }^{29}$, and the substrate MAP2 (Fig. 1c) $)^{30}$.

\section{Validation of CAPN1 and GSK3 $\beta$ as genes transducing G5- induced necrosis}

The involvement of CAPN1 in different necrotic responses is well established ${ }^{31}$. To validate CAPN1 as an effector of the G5-induced necrosis, we silenced its expression using a siRNA targeting a different region of the gene. In addition, a siRNA against PP2AC was used as positive control ${ }^{13}$.

In comparison with the control transfected cells, U87MG cells silenced for CAPN1 or PP2AC were partially protected from G5-induced cell death (Fig. 1d). The potency of the silencing was confirmed by the reduction of the respective protein levels (Fig. 1e).

Next, we validated GSK3 $\beta$ as an element of the G5induced cell death pathway. Its expression was silenced in U87MG and U87MG/BCL-XL cells, with a siRNA targeting a different sequence, respect to those recognized by the shRNAs isolated with the screening. U87MG/BCL-XL cells were used to further exclude the induction of apoptosis. In both cell lines the silencing of GSK3 $\beta$ only modestly decreased G5-induced necrosis (Fig. 1f).

The modest impact of GSK3 $\beta$ silencing in the necrotic pathway triggered by G5 could be the consequence of the low silencing efficiency. In fact, $\sim 40 \%$ of the mRNA is still expressed after transfection (Fig. 1g). To unambiguously clarify this point, we applied the CRISPR/Cas9 system to knock-out GSK3 $\beta$ in U87MG cells (Fig S1a). After the screening of 253 clones, a GSK3 $\beta^{-1-}$ clone (number 19) was identified. The immunoblot analysis demonstrates the complete absence of the GSK3 $\beta$ protein in these cells in comparison with two clones of $G S K 3 \beta^{+/+}$cells, which underwent the same selection (Fig. 1h). The GSK3 $\beta^{+/+}$ control U87MG cells were infected with Cas9 without the sgRNA (indicated as control cells). Clone 63 was infected with both Cas9 and the sgRNA but resulted as a clone still WT for GSK3 $\beta$, after the screening (indicated as WT cells). Genomic DNA Sanger sequencing of GSK3 $\beta$ loci in the three cell lines demonstrated the insertion of a $\mathrm{T}$ in the exon 1, two nucleotides after the PAM, in the KO clone and the presence of a WT GSK3 $\beta$ in the clone 63 and in the WT control (Fig. S1b). The insertion of a T causes the frameshift and the appearance of a STOP codon. Only the first 10 aa of GSK3 $\beta$ can be translated in the GSK3 $\beta^{-I-}$ cells. This event explains the absence of the GSK3 $\beta$ protein (Fig. 1h). Having proved that GSK3 $\beta^{-1-}$ cells do not show overt deficits in their proliferative capacity (Fig. S1c), U87MG/GSK3 $\beta^{+/+}$and U87MG/ GSK3 $\beta^{-1-}$ cells were treated with G5 for $24 \mathrm{~h}$. Similarly to the silenced cells, U87MG/GSK3 $\beta^{-1-}$ cells acquired some 

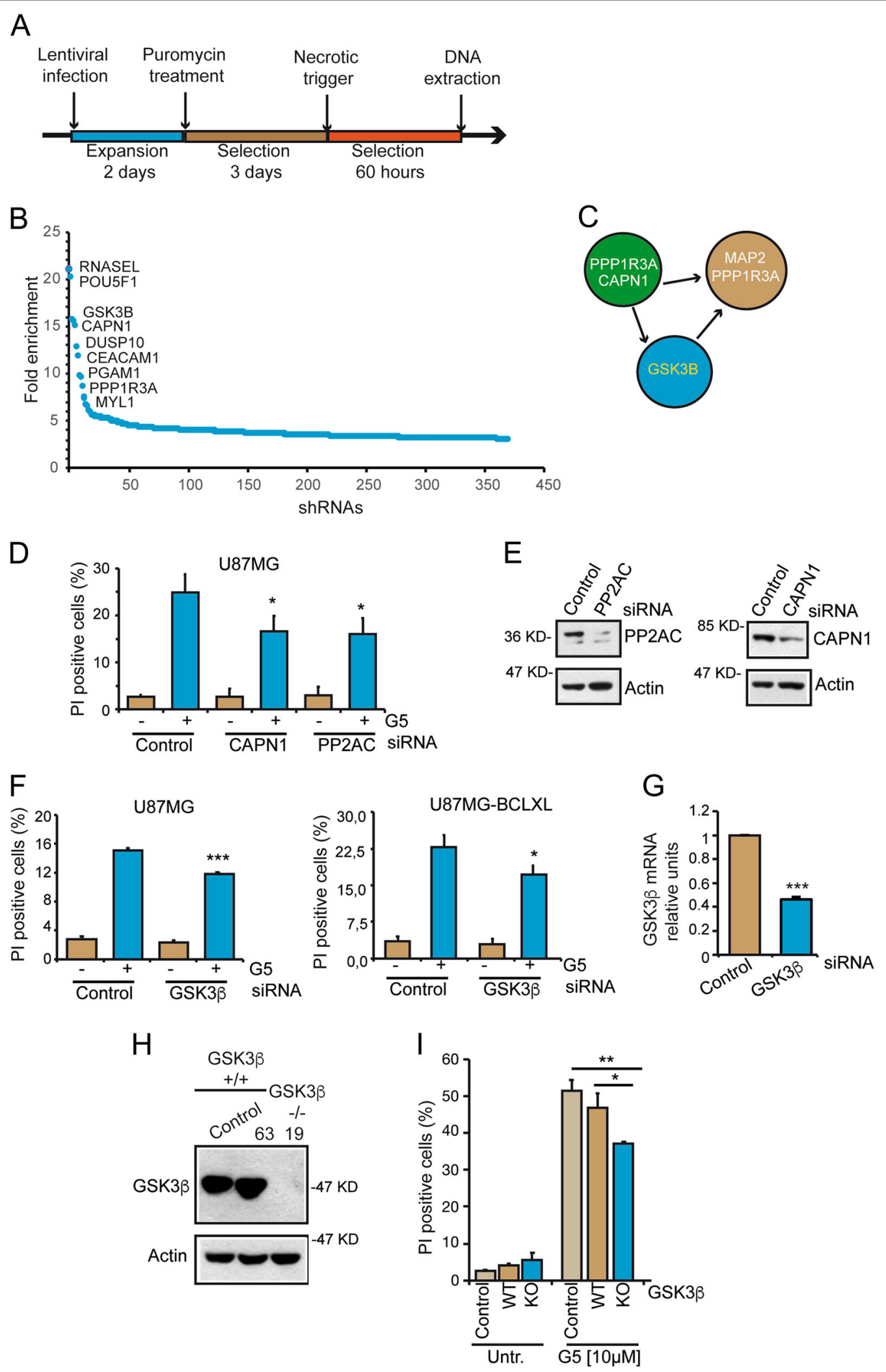

Fig. 1 (See legend on next page.) 
(see figure on previous page)

Fig. 1 Screening protocol and targets validation. a Schematic representation of the screening protocol. $66 \times 10^{6}$ millions of cells were infected with the lentiviral particles containing the shRNA plasmids with a MOl of 0,1 for 2 days. For the selection of the expressing-shRNAs, cells were first grown in the presence of puromycin $(2 \mu \mathrm{g} / \mathrm{ml})$ for additional 3 days and subsequently treated with $\mathrm{G} 5(2.5 \mu \mathrm{M})$ for $60 \mathrm{~h}$. Surviving cells were harvested to recover the genomic DNA. b Representation of the most enriched hits. Data are represented as fold enrichment respect to the median of all shRNAs. The enrichment is relative to the second most abundant shRNA. Only shRNA with a fold increase $>3$ are shown. $\mathbf{c}$ Hits that are in relationship with GSK3 3 as up-stream regulators or downstream effectors. $\mathbf{d}$ U87MG cells were silenced for CAPN1 and PP2AC and, after $48 \mathrm{~h}$ from transfection, they were treated with $\mathrm{G} 5(2.5 \mu \mathrm{M})$ for $24 \mathrm{~h}$. Cell death was calculated as percentage of cells positive to PI staining using cytofluorimetric analysis. Data are from three experiments; +SD. e Cellular lysates from the silenced cells were analyzed by immunoblot. Antibodies anti-CAPN1, antiPP2AC, and anti-Actin (as loading control) were used as indicated. $\mathbf{f}$ U87MG and U87MG-BCLXL cells were silenced for GSK3ß. After $48 \mathrm{~h}$ they were treated with $\mathrm{G} 5(2.5 \mu \mathrm{M})$ for further $24 \mathrm{~h}$. Cell death was calculated as percentage of cells positive to PI staining using cytofluorimetric analysis. Data are from three experiments; +SD. $\mathbf{g}$ qRT-PCR analysis of GSK3 $\beta$ mRNA levels in silenced cells. Data were from three experiments; + SD. $\mathbf{h}$ Immunoblot analysis of GSK3 $\beta$ levels in the indicated clones of U87MG cells, selected after CRISPR/Cas9 mediated knock-out. Actin was used as loading control. i Cytofluorimetric analysis were performed to measure the \% of PI positivity in the different U87MG clones treated with G5 (10 $\mu \mathrm{M})$ for $24 \mathrm{~h}$. Data are presented as mean \pm SD. $n=3$.

resistance to G5-treatment (Fig. 1h). The moderate resistance to G5-treatment is evident only at high concentrations and after prolonged periods of treatment (24 h) with the drug (Fig. S2a, b). This observation further suggests the induction of a necrotic form of cell death. G5-induced cell death is poorly affected by inhibitors of necroptosis or of ferroptosis (Fig. S2a, b). In summary, GSK3 $\beta$ plays a partial contribution in transducing necrotic signals elicited by G5.

\section{GSK3 $\beta$ is a critical transducer of DMNQ-induced oxidative death}

G5 triggers pleiotropic stresses, which can drive cells to death through different pathways. Proteasome impairment, misfolding and proteotoxic stress, oxidative stress and cytoskeletal malfunctions are all hallmarks of the G5induced cell death ${ }^{11-14}$. The partial impact of GSK3 $\beta$ could stem from the co-existence of these multiple pathways. Since GSK3 $\beta$ can be involved in regulating ROS-induced cell death ${ }^{32-35}$, we hypothesized that its involvement in G5-induced death could depend on the ability of the compound of triggering oxidative stress. The impact of G5 on oxidative stress could be direct, through the depletion of glutathione or indirect, through the induction of protein misfolding ${ }^{14}$. To prove this hypothesis, we selected the redox-cycling 2,3-dimethoxy-1,4naphthoquinone (DMNQ), a well-known inducer of oxidative stress. DMNQ toxicity is mediated by ROS production via one-electron-based redox cycling ${ }^{36}$. When U87MG cells were treated with DMNQ, GSK3 $\beta^{-1-}$ cells showed a strong resistance to death (Fig. 2a). To exclude a clone-specific effect, the contribution of GSK3 $\beta$ to DMNQ-induced cell death was validated by RNAi. DMNQ-induced cell death was effectively compromised also after GSK3 $\beta$ silencing (Fig. 2b). The decreased level of GSK3 $\beta$ in the corresponding silenced cells was confirmed by the immunoblot analysis (Fig. 2c). Finally, we proved that also menadione, another quinone, requires GSK3 $\beta$ to efficiently trigger cell death (Fig. S3a). In summary,
GSK3 $\beta$ plays a partial role during G5-induced cell death and a fundamental role during DMNQ-induced cell death.

\section{GSK3 $\beta$ kinase activity is required for DMNQ-induced oxidative necrotic death}

To further confirm the role of GSK3 $\beta$ in transducing DMNQ-induced oxidative death, we re-expressed GSK3 $\beta$ in U87MG/GSK3 $\beta^{-1-}$ cells. The GSK3 $\beta$ wild type (WT) and its kinase dead mutant (KM), carrying the K85A aa substitution were both C-terminal GFP-tagged. As control we also expressed GSK3 $\beta$ and its mutant in U87MG/ GSK $3 \beta^{+/+}$cells. Immunoblot analysis confirmed the expression of the different GSK3 $\beta$ fusions in GSK3 $\beta^{-1-}$ and $G S K 3 \beta^{+/+}$cells (Fig. 2d). The same cells expressing only the neomycin resistance gene were used as control (Neo cells). Cell death in response to DMNQ was recovered only in U87MG/GSK3 $\beta^{-1-}$ cells re-expressing the GSK3 $\beta$-WT. Restoring only GSK3 $\beta$ expression without the catalytic activity (KM mutant) was insufficient to recover the necrotic defect of the $\mathrm{KO}$ cells (Fig. 2e). DMNQ-induced cell death is largely caspase-independent and it is marginally affected by the Ferrostatin-1, an inhibitor of ferroptosis (Fig. S2c, d and Fig. S3c). On the opposite it is strongly dependent on the activity of RIP1, as previously reported ${ }^{13}$. Hence, GSK3 $\beta$ kinase activity is necessary to trigger cell death in response to DMNQ.

GSK3 $\beta$ can also influence cell death by apoptosis ${ }^{37}$. Therefore, to confirm that DMNQ specifically elicits necrosis also in cells overexpressing the kinase, we evaluated caspases activation, the key enzymes of the apoptotic pathway. Caspase- 3 and Caspase- 2 activation and HDAC4 processing (a caspase-3 substrate) were monitored by immunoblot. Cells were also treated with the combination TRAIL/bortezomib a renowned apoptotic stimulus $^{38}$. Figure $2 \mathrm{f}$ shows that GSK3 $\beta$-dependent, DMNQ-induced cell death, does not require caspase activation. On the opposite, U87MG cells, after incubation with TRAIL/bortezomib, strongly activate caspases. 


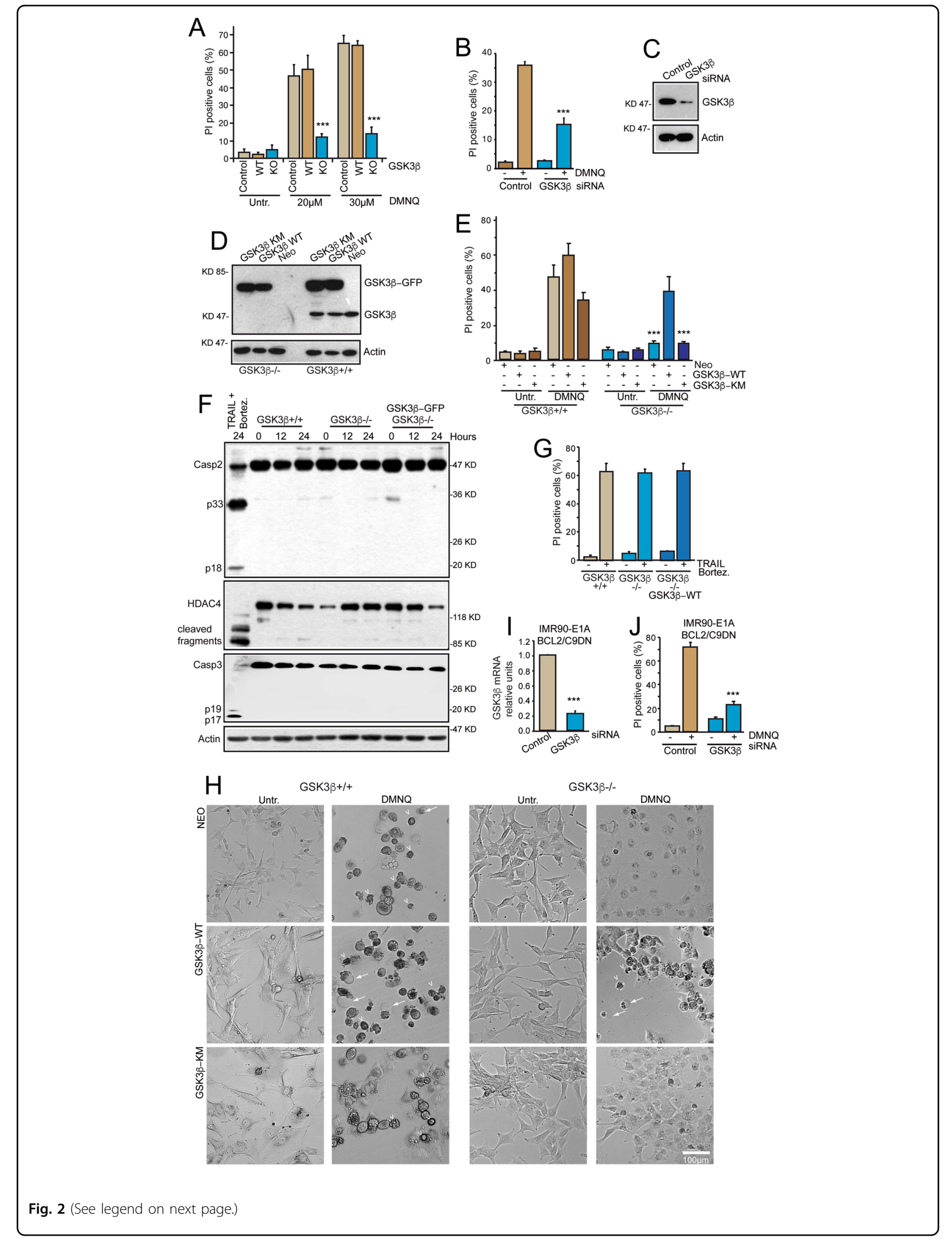


(see figure on previous page)

Fig. 2 GSK3 $\beta$ is necessary for the necrotic response elicited by DMNQ. a Cytofluorimetric analysis measuring cell death percentages (PI positivity) in the different U87MG clones treated with the indicated concentrations of DMNQ for $24 \mathrm{~h}$. Data are presented as mean \pm SD. $n=3 . \mathbf{b}$ Cytofluorimetric analysis measuring cell death percentages (PI positivity). U87MG cells were transfected with siRNAs against GSK3 $\beta$ or control. After $48 \mathrm{~h}$ they were treated with $30 \mu \mathrm{M}$ of DMNQ for further $24 \mathrm{~h}$. Data are presented as mean \pm SD. $n=3$. c Immunoblot analysis of GSK3 $\beta$ levels in U87MG cells transfected with siRNAs against GSK3 $\beta$ or control. Actin was used as loading control. $\mathbf{d}$ Immunoblot analysis of GSK3 3 levels in U87MG GSK3 $\beta^{+/+}$and GSK3 $\beta^{-1-}$ cells retrovirally infected with the GSK3ß-GFP fusions WT or its catalytically inactive mutant K85A (KM). Actin was used as loading control. e Cytofluorimetric analysis measuring cell death percentages (PI positivity) in the indicated U87MG cell lines treated with $30 \mu \mathrm{M}$ of DMNQ for $24 \mathrm{~h}$. Data are presented as mean \pm SD. $n=3$. f Immunoblot analysis of Caspase-3, Caspase-2, and HDAC4 caspase-dependent processing in the indicated U87MG cell lines treated with $30 \mu \mathrm{M}$ of DMNQ. Incubation with the combination TRAIL $(2.5 \mathrm{ng} / \mathrm{ml})$ and bortezomib $(0.1 \mu \mathrm{M})$ for $20 \mathrm{~h}$ was used to trigger apoptosis. Actin was used as loading control. $\mathbf{g}$ Cytofluorimetric analysis measuring cell death percentages (PI positivity) in the indicated U87MG cell lines treated or not with the combination TRAlL $(2.5 \mathrm{ng} / \mathrm{ml})$ and bortezomib $(0.1 \mu \mathrm{M})$ for $24 \mathrm{~h}$. Data are presented as mean \pm SD. $n=3$. $\mathbf{h}$ Microscopic images of the indicated U87MG cell lines treated for $24 \mathrm{~h}$ with DMNQ $(30 \mu \mathrm{M})$. Arrows point to membrane blistering and arrowheads to examples of necrotic cells. Phase contrast images were obtained with Leica DMi1 microscope with a 10x objective. i qRT-PCR analysis of GSK3 $\beta$ mRNA levels in the silenced IMR90-E1A//BCL2/C9DN cells. Data are from three experiments; $+\mathrm{SD}$. $\mathbf{j}$ Cytofluorimetric analysis measuring cell death percentages (PI positivity). IMR90-E1A/BCL2/C9DN cells were transfected with siRNAs against GSK3 $\beta$ or control and after $48 \mathrm{~h}$ treated with $100 \mu \mathrm{M}$ of DMNQ for further $24 \mathrm{~h}$. Data are presented as mean \pm SD. $n=3$.

We also demonstrated that GSK3 $\beta$ is not required for TRAIL/bortezomib-induced apoptosis (Fig. 2h). DMNQinduced cell death showed the features of necrosis, with the appearance of vacuolization and membrane blistering $^{11}$. The appearance of these necrotic features is strictly dependent on the kinase activity of GSK3 $\beta$ (Fig. $2 \mathrm{~h}$ ).

Next, we proved that the role of GSK3 $\beta$ in transducing a necrotic signal is not limited to U87MG cells. We took advantage from IMR90-E1A cells expressing Bcl-2 and a dominant negative mutant of Caspase-9. These engineered cells are resistant to apoptosis and die by necro$\mathrm{sis}^{39}$. The role of GSK3 $\beta$ in the DMNQ-dependent necrotic response was confirmed also in human fibroblasts. When GSK3 $\beta$ was silenced in these cells (Fig. 2i), DMNQ was unable of triggering cell death (Fig. 2j).

\section{DMNQ treatment activates GSK3 $\beta$}

To explore whether GSK3 $\beta$ is activated during DMNQ and G5-induced necrosis, the phosphorylation status of Ser-9 was evaluated. Once phosphorylated, Ser-9 inhibits the kinase activity of GSK3 $\beta$, by acting as a pseudosubstrate $^{40,41}$. Akt is the main up-stream regulator of GSK3 $\beta$ activity, through Ser-9 phosphorylation ${ }^{40,42}$. Hence, we also evaluated Akt activation levels by monitoring Thr308 and Ser-473 phosphorylation status ${ }^{13}$.

In DMNQ-treated cells an early and dramatic dephosphorylation of GSK3 $\beta$ Ser-9 was detected, as soon after $1 \mathrm{~h}$ from treatment, which became stronger after $3 \mathrm{~h}$ (Fig. 3a). The reappearance of Ser-9 phosphorylation after $6 \mathrm{~h}$ could mark the emerging of cells resistant to DMNQ treatment. Akt Thr-308 dephosphorylation parallels the behavior of Ser-9, thus suggesting a direct link between Akt inactivation and GSK3 $\beta$ activation in response to DMNQ. Akt Ser-473 phosphorylation remains unperturbed after DMNQ treatment (Fig. 3a).

Ser-9 dephosphorylation was observed also in response to G5. Here the decrease is modest at early times but appears more consistent at later time-points $(12 \mathrm{~h})$. This delayed activation of GSK3 $\beta$ parallels the inactivation of Akt (Fig. 3b). Overall, GSK3 $\beta$ activation, as monitored by Ser-9 phosphorylation, is modest in G5-treated compared to DMNQ-treated cells.

\section{DMNQ-dependent mitochondrial dysfunctions: the role of GSK3 $\beta$}

DMNQ treatment triggers mitochondrial fragmentation, which depends on Drp1 activities ${ }^{13}$. Smac/DIABLO localization was used to monitor the mitochondrial morphology and the integrity of the outer mitochondrial membrane $(\mathrm{OMM})^{43}$. In GSK3 $\beta^{-/-}$and GSK3 $\beta^{+/+}$ U87MG cells the mitochondrial networks were similar (Fig. 3b). DMNQ treatment triggers mitochondrial fragmentation in both cell lines, which is therefore independent from GSK3 $\beta$. By contrast, SMAC levels were clearly reduced in U87MG/GSK3 $\beta^{+/+}$compared to GSK3 $\beta^{-/-}$ cells (Fig. 3c). Re-expression of GSK3 $\beta$ promoted the decrease of SMAC protein. The degradation of SMAC in response to DMNQ could be related to its release into the cytoplasm as a consequence of the OMM rupture ${ }^{39}$. The alteration of mitochondrial functionality was confirmed by the measure of the mitochondrial membrane potential $\left(\Delta \psi_{\mathrm{m}}\right)$. After $24 \mathrm{~h}$ of DMNQ treatment, $\Delta \psi_{\mathrm{m}}$ is completely collapsed in $G S K 3 \beta^{+/+}$cells but maintained in GSK3 $\beta^{-/-}$ cells (Fig. 3d). As control, incubation with the mitochondrial uncoupler FCCP triggered mitochondrial membrane depolarization in a GSK3 $\beta$ independent manner (Fig. 3d).

\section{$\Delta \psi_{\mathrm{m}}$ dissipation and the nuclear translocation of GSK3 $\beta$}

GSK3 $\beta$ is a pleiotropic kinase involved in multiple signaling pathways. Although it is mainly a cytosolic protein, it can also localize in other subcellular compartments, including the nucleus and the mitochondria ${ }^{44,45}$. Particularly, GSK3 $\beta$ shuttles between the nucleus and the 


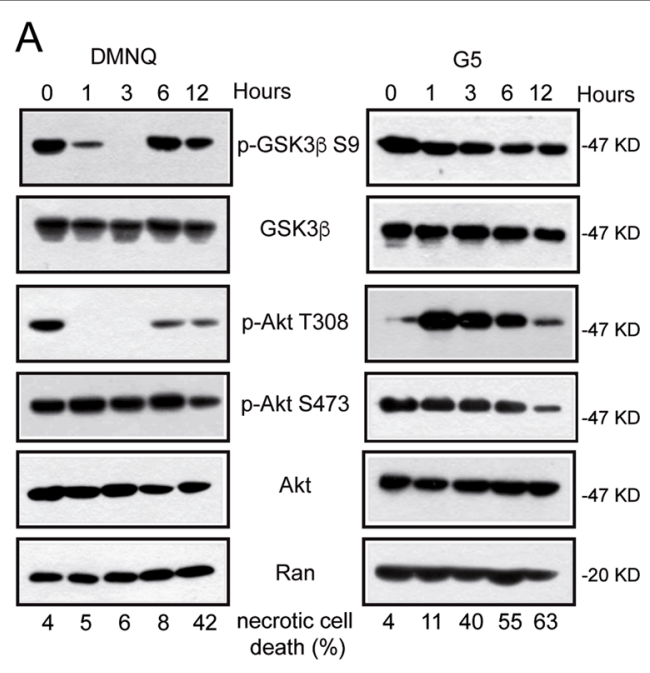

B
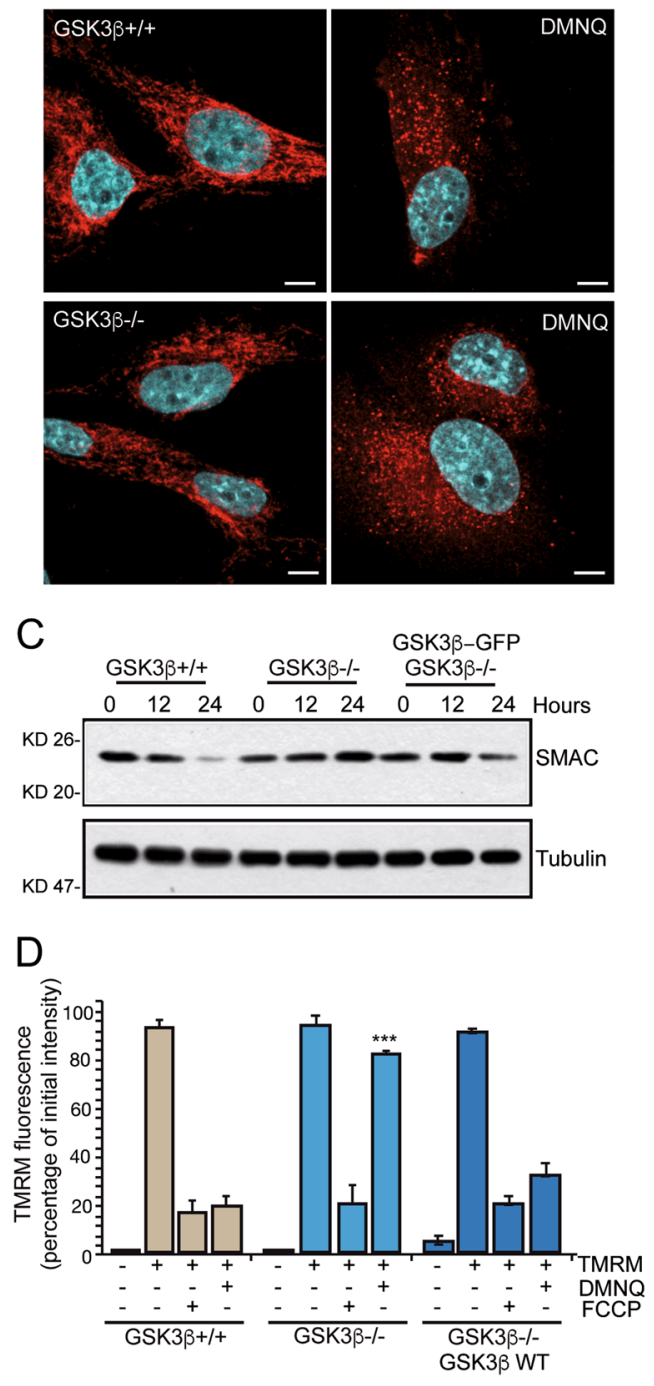

Fig. 3 GSK3 $\beta$ is activated by DMNQ treatment. a U87MG cells were treated with $30 \mu \mathrm{M}$ DMNQ or $10 \mu \mathrm{M}$ G5 for the indicated times. Cellular lysates were generated and immunoblots were performed with the indicated antibodies. In parallel cell death was scored by cytofluorimetric analysis and it is showed at the bottom. $\mathbf{b} \cup 87 \mathrm{MG}$ GSK3 $\beta^{+/+}$and GSK3 $\beta^{-1-}$ cells were treated or not with $30 \mu \mathrm{M}$ DMNQ for $24 \mathrm{~h}$. Immunofluorescence analysis was performed to visualize mitochondria morphology, using anti-SMAC antibodies (red). Nuclei were stained with Hoechst 33258 (cyan). Bar $10 \mu \mathrm{m}$. Confocal images are shown in pseudocolors and were acquired with a Leica SP8 LSM. c Immunoblot analysis of SMAC levels in the indicated U87MG cells treated with $30 \mu \mathrm{M}$ DMNQ for the indicated time points. Actin was used as loading control. d Cytofluorimetric analysis of TMRM fluorescence. The indicated U87MG cells were incubated for $30 \mathrm{~min}$ with TMRM $(1 \mu \mathrm{M})$. FCCP $(10 \mu \mathrm{M})$ was used for $5 \mathrm{~min}$. Data are from three experiments. Columns represent the percentage of initial intensity of TMRM fluorescence + SD.

cytoplasm and a decline of PI3K/Akt activity can favor its nuclear accumulation ${ }^{44}$.

To monitor the subcellular localization of GSK3 $\beta$ in vivo during necrosis, U87MG/GSK3 $\beta^{-1-}$ cells expressing the GSK3 $\beta$-GFP were exposed to DMNQ and subjected to time-lapse confocal microscopy. We also measured in parallel the mitochondrial membrane potential, as a reference of the necrotic death. Figure $4 \mathrm{a}$ shows selected time-frames of the analysis, proving the progressive nuclear accumulation GSK3 $\beta$-GFP, which becomes evident $1 \mathrm{~h}$ before the collapse of $\Delta \psi_{\mathrm{m}}$. Figure $4 \mathrm{~b}$ shows the individual traces for TMRM uptake and GSK3 $\beta$-GFP localization in 10 typical U87MG/GSK3 $\beta^{-/-}$ cells expressing GSK3 $\beta$-GFP, in response to DMNQ. In all examples the progressive nuclear accumulation of GSK3 $\beta$-GFP anticipates $\Delta \psi_{\mathrm{m}}$ collapse. By contrast, when the same analysis was performed in untreated cells, nuclear accumulation of GSK3 $\beta$-GFP was not observed and only "physiological fluctuations" of the $\Delta \psi_{\mathrm{m}}{ }^{46}$ were monitored (Fig. 4c). The integrity of the GSK3 $\beta$-GFP chimera throughout the time of the analysis was verified by immunoblot (Fig. 4d). These data indicate that DMNQ triggers the nuclear accumulation of GSK3 $\beta$-GFP before $\Delta \psi_{\mathrm{m}}$ collapse.

DMNQ-triggered ROS generation requires GSK3 $\beta$ activity

The quinone DMNQ triggers ROS generation after oneelectron reduction by several intracellular flavoenzymes such as the NADPH-cytochrome P450 reductase or nitric oxide synthetases. The product of the one-electron reduction, DMNQ•-, reacts rapidly with $\mathrm{O}_{2}$ to form superoxide anion, $\mathrm{O}_{2} \bullet-$, regenerating DMNQ. This redoxcycle is critical for redox signaling and toxicity ${ }^{36,47}$.

Therefore, we explored whether GSK3 $\beta$ activity was required to sustain the redox cycle. First, we demonstrated that potentiation of the antioxidant properties, by 
A
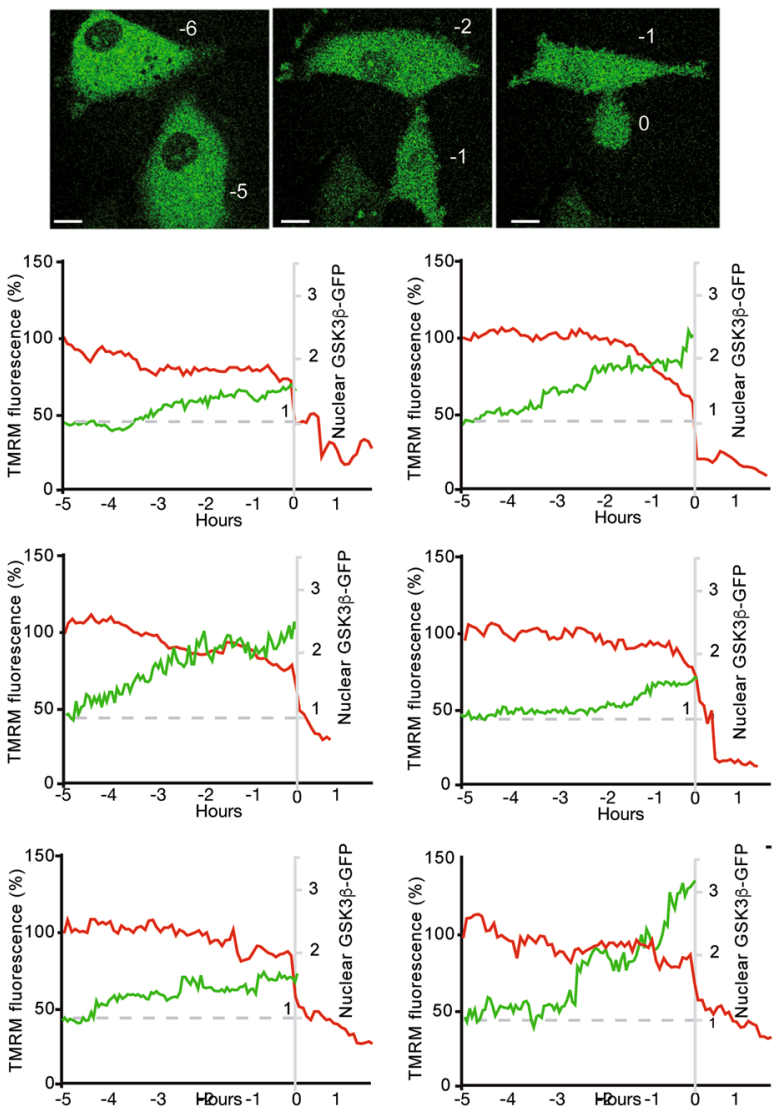

C
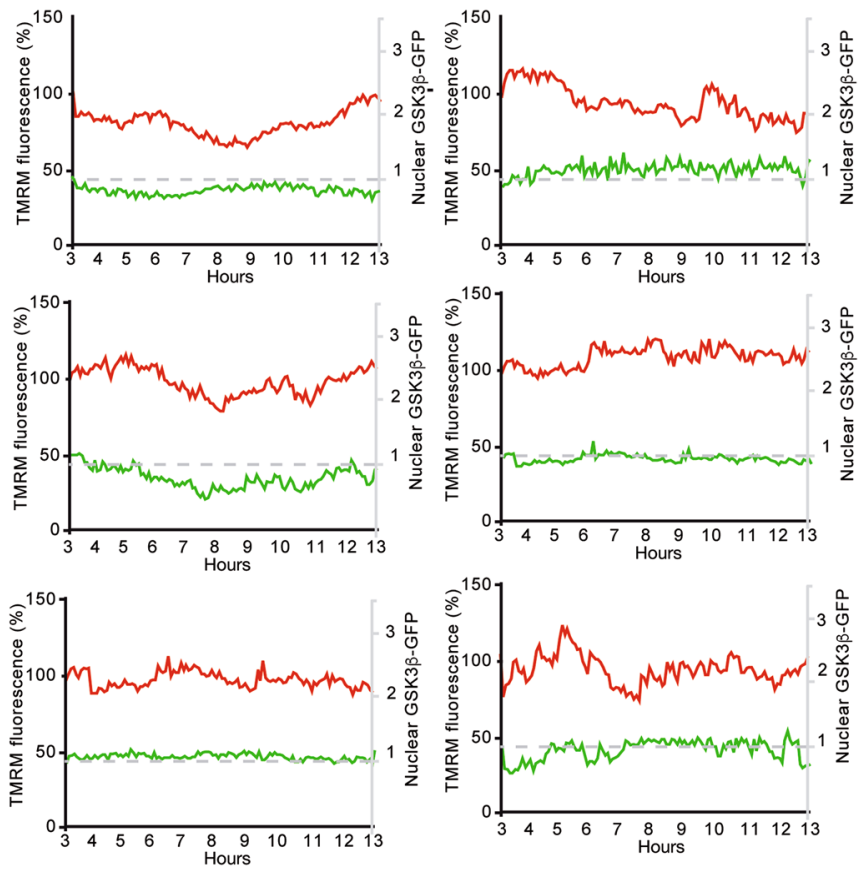
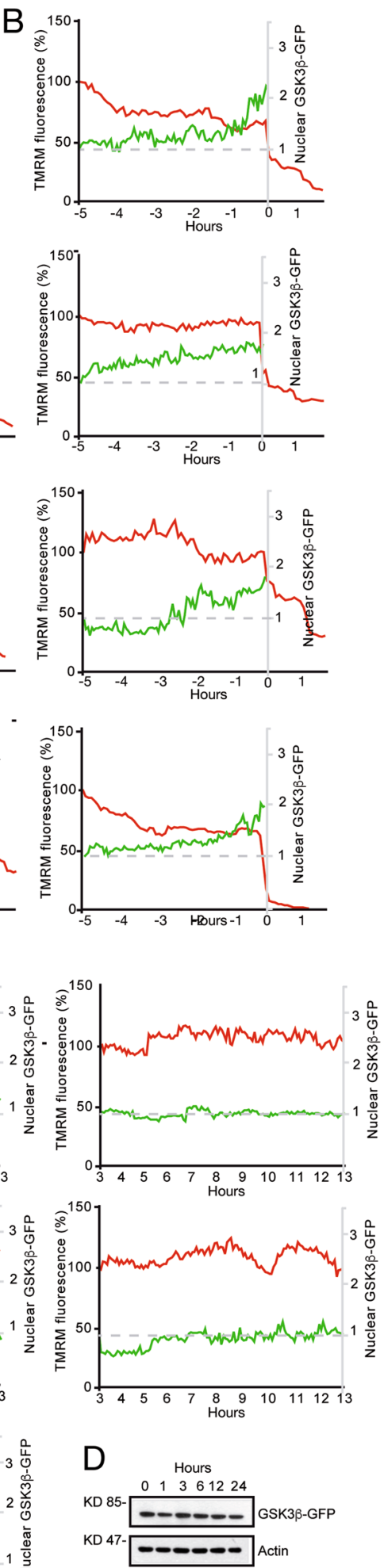

Fig. 4 (See legend on next page.) 
(see figure on previous page)

Fig. 4 Nuclear translocation of GSK3 $\beta$ WT-GFP and mitochondrial $\Delta \psi \mathrm{m}$ dissipation at single cell level in vivo. a Representative frames of two U87MG $/ G S K 3 \beta^{-1-}$ cells re-expressing GSK3 $3 W T-G F P$ treated with $30 \mu \mathrm{M}$ DMNQ. Numbers indicate $h$ before $\Delta \psi_{\mathrm{m}}$ dissipation. Bar $16 \mu \mathrm{m}$. $\mathbf{b}$ Individual traces of cellular TMRM fluorescence (red) and of the nuclear/cytosolic fluorescence of GSK3 $3 W T-G F P$ (green) in U87MG/GSK3 $\beta^{-/-}$cells re-expressing GSK3BWT-GFP. Cells were treated with $30 \mu \mathrm{M}$ DMNQ for $24 \mathrm{~h}$. c Individual traces of cellular TMRM fluorescence (red) and of the nuclear/cytosolic

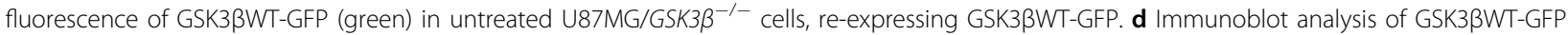
levels in U87MG/GSK3 $\beta^{-/-}$cells treated with $30 \mu \mathrm{M}$ DMNQ for the indicated times. Actin was used as loading control.

treating cells with $\mathrm{N}$-acetylcysteine (NAC), completely abrogates the GSK3 $\beta$-dependent toxicity of DMNQ (Fig. 5a). Next, we compared DMNQ-induced ROS levels, using two different sensors: Carboxy- $\mathrm{H}_{2}$ DCFDA and Deep Red Dye, in the presence or absence of GSK3 3 . DMNQ, through its redox-cycling activity triggers a progressive increase of ROS (Fig. $5 \mathrm{~b}$ ). In the absence of GSK3 $\beta$, after an initial increase, ROS levels droppeddown, reaching a condition similar to the untreated cells. Re-expression of GSK3 $\beta$ restored the ROS accumulation in response to DMNQ (Figs. 5c and S4).

We also monitored the appearance of ROS in response to G5. Differently from DMNQ, G5 triggers a rapid increase of ROS, within $1 \mathrm{~h}$ from treatment, that declines at later times. the contribution of GSK3 $\beta$ is significant also in the case of G5-generated ROS. However, it is much less pronounced, when compared to DMNQ (Fig. 5d).

\section{ROS generation requires GSK3 $\beta$ activity to blunt the} expression of NRF2-target genes involved in the antioxidant response

ROS generation by DMNQ can be prevented by obligatory two-electrons reducing flavoenzymes, such as NQO1 (NAD(P)H quinone dehydrogenase 1) and NQO2. These enzymes, by producing hydroquinones, prevents ROS generation by circumventing one-electron reductase-dependent redox cycling ${ }^{47-49}$. The strong impact of GSK3 $\beta$ on ROS generation could stem from its ability of influencing $N Q O 1$ and NQO2 activities. To verify this hypothesis, we analyzed the expression levels of the two enzymes in U87MG/GSK3 $\beta^{-1-}$ and $G S K 3 \beta^{+/+}$cells treated with DMNQ. qRT-PCR showed that only in response to DMNQ the expression levels of $N Q O 1$ and NQO2 dramatically increase in GSK3 $\beta^{-1-}$ cells. By contrast, only NQO2 expression is modestly up-regulated in GSK3 $\beta^{+/+}$cells (Fig. 5e). We also compared the expression of HMOX1 and GCLM, two genes that belong to the anti-oxidant defense. GCLM is similarly and modestly upregulated in the two cell lines whereas HMOX1 shows a behavior similar to NQO2.

The transcription of these genes in response to oxidative stressors is under the supervision of NRF2 ${ }^{50}$. The activity of this transcription factor is subjected to multiple levels of controls, including half-life variations. In fact,
NRF2 is subjected to proteasomal-mediated degradation, which is suppressed by the oxidative stress ${ }^{50}$.

As expected DMNQ triggers the up-regulation of NRF2. However, in the absence of GSK3 $\beta$, this up-regulation is more pronounced and sustained through the time (Fig. 5f).

To demonstrate the key role of NQO1 and NQO2 in the necrotic response triggered by DMNQ, U87MG/GSK3 $\beta^{+/+}$, GSK $3 \beta^{-1-}$ or $G S K 3 \beta^{-1-}$ expressing GSK3 $\beta$-GFP were treated with dicoumarol a potent inhibitor of NQO1 and tacrine, a recently identified NQO2 inhibitor ${ }^{51,52}$. The resistance to DMNQ-induced necrosis observed in the absence of GSK3 $\beta$ was completely abolished by the inhibition of NQO1, as well as, after the inhibition of NQO2, although less efficiently (Fig. 5g).

In summary, GSK3 $\beta$, through the regulation of NRF2 levels, can blunt the expression of NQO1 and NQO2, two enzymes that prevent ROS generation. In this manner GSK3 $\beta$ can promote cell death by necrosis.

\section{Discussion}

Quinone compounds are ubiquitously diffused in the environment as elements of the food chains or as air pollutants, for example in the diesel exhaust particles ${ }^{53}$. Quinones can also be generated in the body as a result of some xenobiotic metabolism through the cytochrome P450 system ${ }^{36}$. DMNQ has been intensively studied as an example of quinones toxicity. DMNQ toxicity is mediated by ROS production via one-electron-based redox cycling. Several flavoenzymes, including NADPH-cytochrome $\mathrm{P} 450$ reductase and NADH-cytochrome b reductase, can fulfil the one-electron reduction of $\mathrm{DMNQ}^{36,47,48}$. For this reason DMNQ is also commonly used, as a tool, to investigate the cellular responses to the oxidative stress.

In this manuscript we have demonstrated that GSK3 $\beta$ is a key player of the DMNQ/ROS-induced necrotic death. We show that GSK3 $\beta$ is responsible for reducing the antioxidant response engaged by NRF2. This response leads the up-regulation of the obligatory two-electron reducing flavoenzymes $\mathrm{NQO} 1$ and $\mathrm{NQO} 2^{47,48,51,52}$. These flavoenzymes are required to blunt the redox cycling activity of DMNQ. In the absence of GSK3 $\beta$, NRF2 levels and the transcription of its targets $\mathrm{NQO1}$ and $\mathrm{NQO} 2$ is strongly sustained. In this manner the cytotoxic effect of quinones is nullified (Fig. 6). 
A

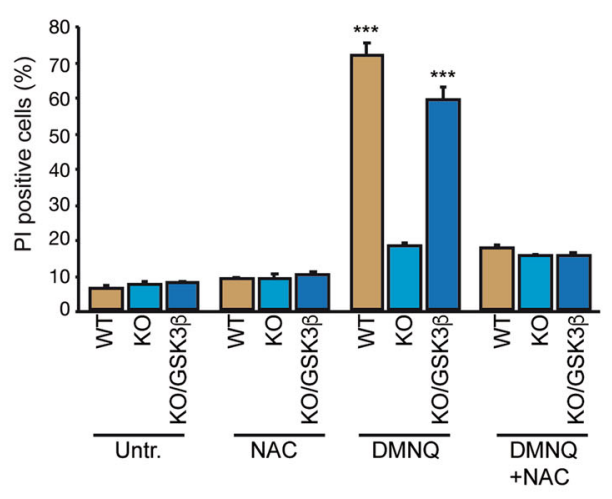

E
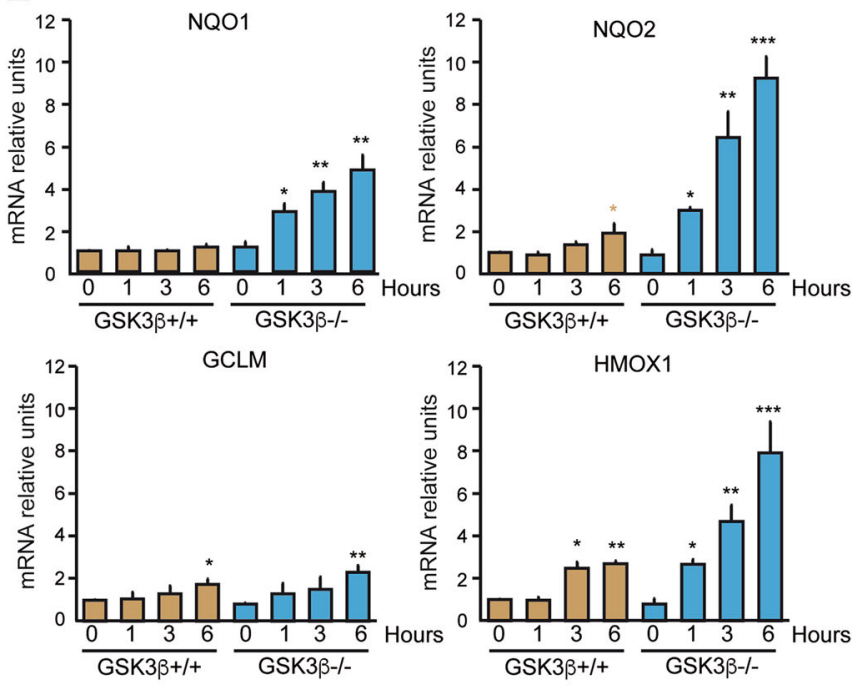

$\mathrm{F}$
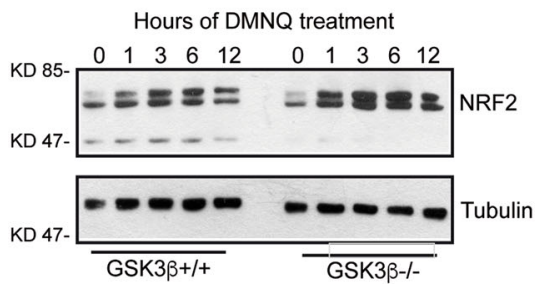

B

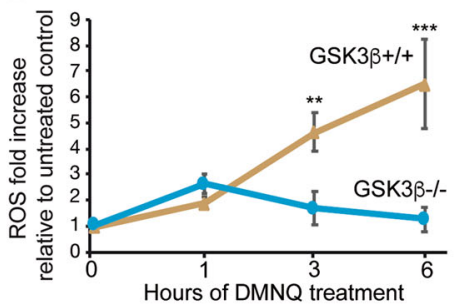

C
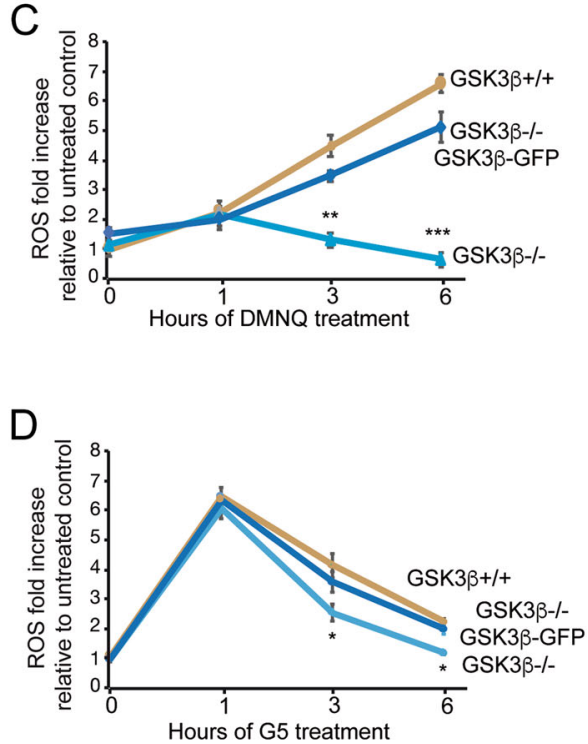

Fig. 5 GSK3 $\beta$ favors ROS generation in response to DMNQ. a Cytofluorimetric analysis measuring cell death percentages (PI positivity) in the indicated U87MG cell lines, treated or not with the indicated combinations of molecules. DMNQ was used $30 \mu \mathrm{M}$. N-acetylcysteine (NAC) was 5 mM. Incubation was for $24 \mathrm{~h}$. Data are presented as mean \pm SD. $n=3$. b Levels of reactive oxygen species as measured by Carboxy- $\mathrm{H}_{2} \mathrm{DCFDA}$ fluorescence in U87MG GSK3 $\beta^{+/+}$and GSK3 $\beta^{-1-}$ cells treated with $30 \mu \mathrm{M}$ DMNQ. c Levels of reactive oxygen species as measured by ROS Deep Red Dye fluorescence in the indicated U87MG cell lines treated with $30 \mu \mathrm{M}$ DMNQ. $\mathbf{d}$ Levels of reactive oxygen species as measured by ROS Deep Red Dye fluorescence in the indicated U87MG cell lines treated with $10 \mu \mathrm{M}$ G5. e Time-course analysis of NQO1, NQO2, HMOX1 and GCLM mRNA expression levels. U87MG GSK3 $\beta^{+/+}$and GSK3 $\beta^{-1-}$ cells were treated with $30 \mu \mathrm{M}$ of DMNQ for the indicated times and the mRNA levels were monitored by qRTPCR. Data are from three experiments; +SD. f Immunoblot analysis of NRF2 levels in U87MG GSK3 $\beta^{+/+}$and GSK3 $\beta^{-/-}$cells treated with $30 \mu M$ DMNQ for the indicated times. Actin was used as loading control. $\mathbf{g}$ Cytofluorimetric analysis measuring cell death percentages (PI positivity) in the indicated U87MG cell lines, treated or not with the indicated combinations of molecules. DMNQ was used $30 \mu \mathrm{M}$, Dicoumarol $100 \mu \mathrm{M}, \mathrm{Tacrine} 20 \mu \mathrm{M}$. Incubation was for $24 \mathrm{~h}$. Data are presented as mean \pm SD. $n=3$. 


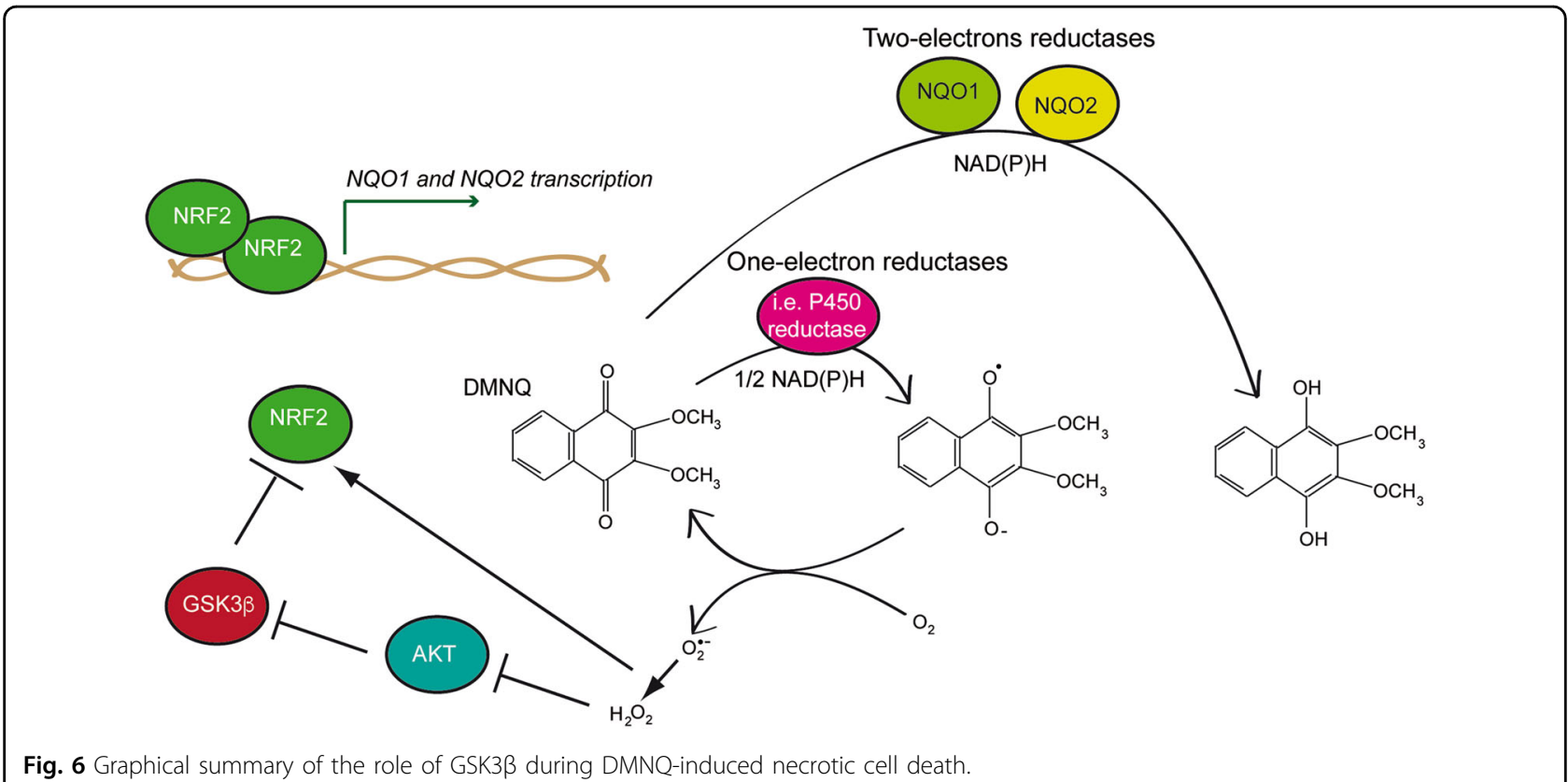

Our results suggest a model where high ROS levels, as generated by DMNQ, inhibit $\mathrm{AKT}^{13,54}$ and consequently unleash GSK3 $\beta$ activity, which in turn, switches-off the NRF2 anti-oxidant responses ${ }^{50,55,56}$. Hence, the impact of GSK3 $\beta$ in this necrotic pathway is mainly exerted by suppressing a pro-survival signal (Fig. 6).

The described pathway is pathological relevant and it is implicated in other models of cell death elicited by oxidative stress. Examples are the ischemia and reperfusion injury in the brain ${ }^{57}$, in hepatocytes ${ }^{58,59}$, during diabetic nephropathies ${ }^{60}$, in a model for Alzheimer disease ${ }^{61}$ and in other models of neurological diseases ${ }^{62,63}$.

The time-lapse analysis suggests that the DMNQdependent nuclear accumulation of GSK3 $\beta$ anticipates the $\Delta \psi_{\mathrm{m}}$ collapse. Hence, it is plausible that GSK3 $\beta$ activation is coupled to its nuclear accumulation where it phosphorylates NRF2, a signal necessary for its nuclear exclusion, its poly-ubiquitylation and the subsequent proteasomal degradation ${ }^{44,64}$.

GSK3 $\beta$ was identified after a high-throughput shRNA screening, aimed to define new players of the necrotic response induced by G5. Unexpectedly, the kinase plays only a minor role in this form of death. In agreement with our observation GSK3 $\beta$ activation is much less evident in response to G5 compared to DMNQ. Even though we have demonstrated that G5 is able to trigger oxidative stress.

We suggest that Akt could explanation this apparent paradox. Akt in response to G5 is not dephosphorylated at early time points, differently from DMNQ. Instead we confirmed a strong increase of Thr 308 phosphorylation, as previously reported ${ }^{13}$. The two cysteine residues 310 and 296 found in the T-loop region are critical for Akt activity. We have recently shown that G5 can directly target Akt, possibly by reacting with these cysteines residues ${ }^{15}$. Hence G5 could directly interfere with Akt activities. How it could occur and which could be the consequence on Akt activity, deserve further investigations.

Finally, we have not completely unveiled the molecular basis of the necrotic pathway elicited by G5. GSK3 $\beta$ and the oxidative stress probably play only a secondary or additive role in this pathway. During the investigation of the role of GSK3 $\beta$, we also tested the contribution of other genes, which were included among the top hits of the screening. Transfection of isolated siRNAs only minimally reduced G5-induced cell death. It is plausible that, the simultaneous induction of multiple stresses by G5 causes multiple cellular dysfunctions that ultimately trigger necrosis. Under this condition, ablation of a single gene is not enough to rescue cells from the death commitment.

\section{Materials and methods}

\section{Cell culture conditions and reagents}

The cell lines used in this article were Uppsala 87 Malignant Glioma (U87MG) glioblastoma cell line, IMR90-E1A lung fibroblast cell line, Human Embryonic Kidney cells 293 T1 (HEK293T1) cell line and Phoenix Amphotropic (AMPHO) embryonic kidney cell line. All cell lines were cultured at $37^{\circ} \mathrm{C}$ in $5 \% \mathrm{CO}_{2}$ atmosphere in Dulbecco's Modified Eagle's Medium (DMEM), (SigmaAldrich) supplemented with $10 \%$ fetal bovine serum 
(FBS); glutamine $(2 \mathrm{mmol} / \mathrm{L})$, penicillin $(100 \mathrm{U} / \mathrm{mL})$ and streptomycin $(100 \mu \mathrm{g} / \mathrm{mL})$ (Euroclone). All cell lines were tested for mycoplasma contamination and resulted as mycoplasma free. U87MG cells were authenticated by gene expression profile. U87MG/BCL-XL and IMR90/ E1A/BCL-2/C9DN cells, expressing a dominant negative mutant of caspase- 9 were previously described ${ }^{11,12}$ and verified for the expression of the transgenes. The following chemicals were used: $4 \mathrm{H}$-thiopyran-4-one, tetrahydro3,5-bis[(4-nitrophenyl) methylene]-1,1-dioxide $(\mathrm{G} 5)^{10}$; 2,3-dimethoxy-1,4-naphthoquinone (DMNQ); carbonilcyanide $p$-triflouromethoxyphenylhydrazone (FCCP); NAC; Propidium Iodide (PI), Ferrostatin-1 and DMSO (Sigma Aldrich); Tetramethyl Rhodamine Methyl-ester (TMRM) (Life Technologies); Bortezomib (LC Laboratories); TNF-related apoptosis-inducing ligand (TRAIL) ${ }^{65}$; G418 (Euroclone); Hygromycin (PanReac-AppliChem); Dicoumarol and Tacrine (Santa Cruz Biotechnology); Necrostatin-1 (Enzo Life Sciences); Boc-D-FMK (Abcam).

\section{shRNA library screening}

U87MG cells were transduced with DECIPHER Pooled shRNA library-Human Module 1 (Cellecta, Mountain View, CA, USA) composed by 27500 shRNAs targeting 5043 genes (5-6 shRNAs/mRNA). The HTS3 (DECIPHER pRSI9-U6-(sh)-HTS3-UbiC-TagRFP-2A-Puro-dW) cassette of each shRNA contains the U6 RNA polymerase III promoter to drive shRNAs expression, the fluorescence protein (RFP) and the puromycin resistance. All shRNAs have unique 18-nucleotide DNA barcode sequences, which facilitate their identification after HT sequencing. The HEK293T1 packaging cells were transfected with $60 \mu \mathrm{g}$ of the plasmid shRNAs library and $300 \mu \mathrm{g}$ of the packaging plasmid mix (Cellecta Inc., psPAX2: pMD2.G), in DMEM without serum or antibiotics and in the presence of Plus Reagent ${ }^{\mathrm{TM}}$ and Lipofectamin ${ }^{\mathrm{TM}}$ (Life Technologies). The concentrated lentiviral particles were re-suspended in PBS with $10 \% \mathrm{FBS}$ and stored at $-80^{\circ} \mathrm{C}$ for the lentiviral titer estimation. After the calculation of the Transduction Units, $66 \times 10^{6}$ cells were transduced with the shRNA library at MOI of 0.1 to ensure that $~ 90 \%$ of the cells are infected with one shRNA-carrying virus. After $48 \mathrm{~h}$, infected cells were selected by adding Puromycin $(2 \mu \mathrm{g} / \mathrm{ml})$ for $72 \mathrm{~h}$. Later, the selected cells were treated with G5 $(2.5 \mu \mathrm{M})$ for $60 \mathrm{~h}$. Genomic DNA (gDNA) was purified from the surviving cells using the QIAamp DNA Micro Kit (Qiagen, Hilden, Germany). Pooled barcodes were PCR-amplified from $100 \mu \mathrm{g}$ of gDNA and identified after Illumina sequencing by deconvolution analysis. Positive hits were selected as genes when at least two different shRNAs scored higher frequencies in comparison to the average of the control luciferase $(n \geq 3)$.

\section{RNA interference}

The RNA interference (RNAi) was performed using the following siRNAs direct against: CAPN1 (Santa Cruz Biotechnology); PP2Ac (Life Technologies); GSK3 $\beta$ (Fw 5'-GCAUUUAUCGUUAACCUAA-3'， Rv 5'-UUAGGU UAACGA UAAAUGC - 3', Sigma Aldrich); or the relative control siRNAs. U87MG, U87MG/BCL-XL and IMR90/ E1A/BCL-2/C9DN cells were transfected $24 \mathrm{~h}$ after seeding. Six hours later the medium was changed, and after $48 \mathrm{~h}$ of silencing, cells were treated with G5 or DMNQ for further $24 \mathrm{~h}$. RNA was extracted and the protein lysates were collected for the subsequent analysis.

\section{Drug treatments, $\mathrm{PI}$ - and TMRM-assay}

For cytofluorimetric analysis, drug treated cells were collected in PBS and incubated with propidium iodide (PI) for $5 \mathrm{~min}$ at room temperature. PI fluorescence was determined by the FACSCalibur flow cytometer (BD, San Jose, $\mathrm{CA}$,) at the excitation wavelength of $585 \mathrm{~nm}$. For TMRM assay, cells were incubated with TMRM $(1 \mu \mathrm{M})$ for $30 \mathrm{~min}$. TMRM fluorescence was determined by flow cytometer at the excitation wavelength of $488 \mathrm{~nm}$.

\section{Cell lysis and Western Blotting}

The cellular lysis was performed using an SDS denaturing lysis solution in which the protease inhibitor cocktail (PIC), phenylmethane sulfonyl fluoride (PMSF), $\mathrm{Na}_{3} \mathrm{VO}_{4}$ and $\beta$-mercaptoethanol were added. After SDS/ PAGE electrophoresis proteins were transferred to a $0.2 \mu \mathrm{m}$-pore-sized nitrocellulose membrane. Immunoblotting was performed as previously described ${ }^{11}$. The used primary antibodies were: anti-PP2Ac (Upstate, 05545); anti-actin (Sigma-Aldrich, A2066); anti-CAPN1 (sc271313), anti-GSK3 $\beta$ (sc-377213) and anti-NRF2 (sc365949) (Santa Cruz Biotechnology); anti-p-GSK3 $\beta$ S9 (9336), anti-p-Akt T308 (4056); anti-p-Akt T473 (9271), anti-Akt (9272), anti-Caspase-3 (9662) (Cell Signaling Technology), anti-Smac/DIABLO ${ }^{39}$ and anti-HDAC4 ${ }^{66}$; anti-Caspase- $2^{67}$; anti-tubulin ${ }^{67}$. The same membranes were incubated with the horseradish peroxidaseconjugated secondary antibody for $1 \mathrm{~h}$ at room temperature. The used secondary antibodies were goat anti-mouse or goat anti-rabbit (Sigma Aldrich). Finally, the blots were developed using Super Signal West Dura as recommended by the vendor (Pierce Waltham, MA, USA).

\section{RNA extraction and qRT-PCR}

Cells were lysed using Tri-Reagent (Molecular Research Center). $1.0 \mu \mathrm{g}$ of total RNA was retro-transcribed by using 100 units of M-MLV Reverse transcriptase (Life Technologies). qRT-PCRs were performed using SYBR green technology (KAPA Biosystems). Data were analyzed 
by comparative threshold cycle using $H P R T$ and GAPDH as normalizer.

\section{Generation of GSK3 $\beta$ knock-out U87MG cells}

U87MG cells null for GSK3 $\beta$ were achieved using the CRISPR/Cas9 technology. The single guide RNA (sgRNA) 5'-CCTTTGCGGAGAGCTGCAAG-3' was designed using "CRISPR design" tool (http://crispr.mit.edu/). Lentiviral infections and selections were performed as previously described ${ }^{68}$. The $\mathrm{KO}$ clones were screened by PCR, immunoblots and validated by Sanger sequencing.

\section{Generation of U87MG/GSK3 $\beta^{-1-}$ cells expressing GSK3 $\beta$ WT and its mutant K/M fused to GFP}

The coding sequence of GSK3 $\beta$ was amplified by PCR from Vectors encoding wild-type and kinase-dead GSK3 $\beta$ previously described ${ }^{69}$, using the following primers (Sigma-Aldrich): - AGATCTATGTCAGGGCGGCCC AG, as forward primer containing a restriction site for $B g l$ II; - GAATTCTGGTGGAGTTGGAAGCTGATG, as reverse primer containing the EcoRI site. GSK3 $\beta$ WT and the kinase defective mutant KM were cloned into pEGFPN1 plasmid. Next the two fusions (GSK3 $\beta /$ WT-GFP and GSK3 $3 /$ KM-GFP) digested $B g l \mathrm{II}$ and $X h o \mathrm{I}$ were subcloned into the retroviral vector pWZL-Neo. U87MG cells expressing BCL-XL, GSK3 $\beta$-WT-GFP or GSK3 $\beta / \mathrm{KM}$ GFP constructs were generated by retroviral infection as previously described ${ }^{12}$. G418 $(1000 \mu \mathrm{g} / \mathrm{ml})$ for the selection of GSK3 $\beta$-WT-GFP or KM-GFP expressing cells and Hygromycin $(200 \mu \mathrm{g} / \mathrm{ml})$ for the selection of BCL-XL expressing cells were used. As control U87MG cells were infected with pWZL-Hygro and pWZL-Neo retroviral vectors and selection performed as above described.

\section{Immunofluorescences and time-lapse microscopy}

U87MG cells were fixed with 3\% paraformaldehyde and permeabilized with $0.5 \%$ Triton X-100. The primary antibody was anti-Smac/DIABLO, and the secondary antibody was Alexa Fluor 546-conjugated anti-rabbit (Life Technologies). Cells were imaged with a Leica confocal microscopy SP2 or SP8.

For time-lapse analysis TMRM $(20 \mathrm{nM})^{39}$ was used and DMNQ $(30 \mu \mathrm{M})$ added $1 \mathrm{~h}$ before the analysis. The images were collected every $5 \mathrm{~min}$ for $24 \mathrm{~h}$ using a Leica SP8 confocal microscope (Leica Microsystems) equipped with a stage top incubator controlling temperature, $\mathrm{CO}_{2}$ and humidity (Okolab). Image analysis was performed using the Leica Acquired Software X (LASX). For the TMRM $\Delta \psi_{\mathrm{m}}$ analysis, the fluorescence of the mitochondria was evaluated through drawing a region around the cell (Region Of Interest; ROI) and measuring its Mean fluorescence Intensity ( $\left.\mathrm{MI}_{\mathrm{TMRM}} \mathrm{mell}\right)$. The fluorescence of the background ( $\left.\mathrm{BK}_{\mathrm{TMRM}}\right)$, which is another ROI located in a non-fluorescent region, was subtracted to the $\mathrm{MI}_{\mathrm{TMRM}}$ cell and the obtained data was multiplied for the area of the cell $\left(\right.$ Area $\left._{\text {cell }}\right)$, according to the following equation:

TMRM fluorescence $(\%)=\left(\mathrm{MI}_{\mathrm{TMRMcell}}-\mathrm{BK}_{\mathrm{TMRM}}\right) *$ Area $_{\text {cell }}$

A similar calculation was used to quantify the increase of nuclear fluorescence of GSK3 $\beta$-GFP, according to the following formula:

$$
\begin{aligned}
& \text { Nuclear GSK3 } \beta-\text { GFP }=\left(\mathrm{MI}_{\mathrm{GSK} 3 \beta-\mathrm{GFPnucl}}-\mathrm{BK}_{\mathrm{GSK} 3 \beta-\mathrm{GFP}}\right) * \text { Area }_{\text {nucl }} \\
& /\left(\mathrm{MI}_{\mathrm{GSK} 3 \beta-\mathrm{GFP} \text { cytosol }}-\mathrm{BK}_{\mathrm{GSK} 3 \beta-\mathrm{GFP} \text { cytosol }}\right) * \text { Area }_{\text {cytosol }}
\end{aligned}
$$

\section{ROS accumulation measurement}

The reactive oxygen species (ROS) accumulation was evaluated using two different probes following the manufacturer's instructions: 6-carboxy-2',7'-dichlorodihydrofluorescein diacetate (Carboxy- $\mathrm{H}_{2}$ DCFDA) (Life Technologies) and the ROS Deep Red Dye from the Cellular Reactive Oxygen Species Detection Assay Kit Deep Red Fluorescence (Abcam). Carboxy- $\mathrm{H}_{2}$ DCFDA and ROS Deep Red Dye fluorescence were determined by the FACSCalibur flow cytometer (BD) at the excitation wavelength of $495 \mathrm{~nm}$ for Carboxy- $\mathrm{H}_{2}$ DCFDA and $650 \mathrm{~nm}$ for the ROS Deep Red Dye.

\section{Statistics}

Results were expressed as means \pm standard deviations (SD) from at least three independent experiments. Statistical analysis of differences between groups was performed using the Student's $t$ test of Excel software (two-samples, two-tailed distribution, equal variance), with $p$ values represented as: ${ }^{*} p<0.05$; ${ }^{* * *} p<0.01$; ${ }^{* * *} p<$ 0.005 . Measurements were obtained in double-blind.

\section{Acknowledgements}

This work was supported by grant from Regione Friuli-Venezia Giulia POR FESR 2014-2020 ATeNA. We thank Raffaella Picco (DAME UniUD) for helping in data analysis.

Conflict of interest

The authors declare that they have no conflict of interest.

\section{Publisher's note}

Springer Nature remains neutral with regard to jurisdictional claims in published maps and institutional affiliations.

Supplementary Information accompanies this paper at (https://doi.org/ 10.1038/s41419-019-2202-0).

Received: 9 July 2019 Revised: 11 December 2019 Accepted: 12 December 2019

Published online: 02 January 2020 


\section{References}

1. Tuzlak, S., Kaufmann, T. \& Villunger, A. Interrogating the relevance of mitochondrial apoptosis for vertebrate development and postnatal tissue homeostasis. Genes Dev. 30, 2133-2151 (2016).

2. Lindsten, T. \& Thompson, C. B. Cell death in the absence of Bax and Bak. Cell Death Differ. 13, 1272-1276 (2006).

3. Jorgensen, I., Rayamajhi, M. \& Miao, E. A. Programmed cell death as a defence against infection. Nat. Rev. Immunol. 17, 151-164 (2017).

4. Redza-Dutordoir, M. \& Averill-Bates, D. A. Activation of apoptosis signalling pathways by reactive oxygen species. Biochim. Biophys. Acta 1863, 2977-2992 (2016).

5. Fearnhead, H. O., Vandenabeele, P. \& Vanden Berghe, T. How do we fit ferroptosis in the family of regulated cell death? Cell Death Differ. 24 1991-1998 (2017).

6. Green, D. R. \& Llambi, F. Cell death signaling. Cold Spring Harb. Perspect. Biol. 7, a006080 (2015).

7. Tang, D., Kang, R., Berghe, T. V., Vandenabeele, P. \& Kroemer, G. The molecular machinery of regulated cell death. Cell Res. 29, 347-364 (2019).

8. Conrad, M. et al. Regulation of lipid peroxidation and ferroptosis in diverse species. Genes Dev. 32, 602-619 (2018).

9. Friedmann Angeli, J. P., Krysko, D. V. \& Conrad, M. Ferroptosis at the crossroads of cancer-acquired drug resistance and immune evasion. Nat. Rev. Cancer 19 405-414 (2019).

10. Aleo, E., Henderson, C. J., Fontanini, A., Solazzo, B. \& Brancolini, C. Identification of new compounds that trigger apoptosome-independent caspase activation and apoptosis. Cancer Res. 66, 9235-9244 (2006).

11. Fontanini, A. et al. The isopeptidase inhibitor G5 triggers a caspaseindependent necrotic death in cells resistant to apoptosis: a comparative study with the proteasome inhibitor bortezomib. J. Biol. Chem. 284, 8369-8381 (2009).

12. Foti, C. et al. Characterization of caspase-dependent and caspase-independent deaths in glioblastoma cells treated with inhibitors of the ubiquitinproteasome system. Mol. Cancer Ther. 8, 3140-3150 (2009).

13. Tomasella, A., Blangy, A. \& Brancolini, C. A receptor-interacting protein 1 (RIP1)independent necrotic death under the control of protein phosphatase PP2A that involves the reorganization of actin cytoskeleton and the action of cofilin1. J. Biol. Chem. 289, 25699-25710 (2014).

14. Tomasella, A. et al. The isopeptidase inhibitor 2cPE triggers proteotoxic stress and ATM activation in chronic lymphocytic leukemia cells. Oncotarget 7, 45429-45443 (2016)

15. Ciotti, $\mathbf{S}$. et al. The binding landscape of a partially-selective isopeptidase inhibitor with potent pro-death activity, based on the bis(arylidene)cyclohexanone scaffold. Cell Death Dis. 9, 184 (2018).

16. Anchoori, R. K. et al. Stressing the ubiquitin-proteasome system without $20 \mathrm{~S}$ proteolytic inhibition selectively kills cervical cancer cells. PLOS ONE 6, 23888 (2011).

17. Shukla, N. et al. Proteasome addiction defined in ewing sarcoma is effectively targeted by a novel class of 195 proteasome inhibitors. Cancer Res. 76 , 4525-4534 (2016).

18. Coughlin, K. et al. Small-molecule RA-9 inhibits proteasome-associated DUBs and ovarian cancer in vitro and in vivo via exacerbating unfolded protein responses. Clin. Cancer Res. 20, 3174-3186 (2014).

19. Cersosimo, U. et al. Synthesis, characterization, and optimization for in vivo delivery of a nonselective isopeptidase inhibitor as new antineoplastic agent. J. Med. Chem. 58, 1691-1704 (2015).

20. D'Arcy, P. et al. Inhibition of proteasome deubiquitinating activity as a new cancer therapy. Nat. Med. 17, 1636-1640 (2011).

21. Wang, $X$. et al. The 195 Deubiquitinase inhibitor b-AP15 is enriched in cells and elicits rapid commitment to cell death. Mol. Pharmacol. 85, 932-945 (2014).

22. Karki, S. S. et al. Synthesis and biological evaluation of novel 2-aralkyl-5-substituted-6-(4'-fluorophenyl)-imidazo[2,1-b][1,3,4]thiadiazole derivatives as potent anticancer agents. Eur. J. Med. Chem. 46, 2109-2116 (2011).

23. Robertson, H., Hayes, J. D. \& Sutherland, C. A partnership with the proteasome; the destructive nature of GSK3. Biochem. Pharmacol. 147, 77-92 (2018),

24. Reddy, P. H. Amyloid beta-induced glycogen synthase kinase $3 \beta$ phosphorylated VDAC1 in Alzheimer's disease: implications for synaptic dysfunction and neuronal damage. Biochim Biophys. Acta 1832, 1913-1921 (2013).

25. Ghaderi, S. et al. Role of glycogen synthase kinase following myocardial infarction and ischemia-reperfusion. Apoptosis 22, 887-897 (2017).
26. Wakatsuki, S., Tokunaga, S., Shibata, M. \& Araki, T. GSK3B-mediated phosphorylation of MCL1 regulates axonal autophagy to promote Wallerian degeneration. J. Cell Biol. 216, 477-493 (2017).

27. Gu, C. et al. P7C3 inhibits GSK3 3 activation to protect dopaminergic neurons against neurotoxin-induced cell death in vitro and in vivo. Cell Death Dis. 8 2858 (2017).

28. Goñi-Oliver, P., Lucas, J. J., Avila, J. \& Hernández, F. N-terminal cleavage of GSK3 by calpain: a new form of GSK-3 regulation. J. Biol. Chem. 282, 22406-22413 (2007).

29. Felgueiras, J. \& Fardilha, M. Phosphoprotein phosphatase 1-interacting proteins as therapeutic targets in prostate cancer. World J. Pharm. 3, 120-139 (2014).

30. Sánchez, C., Tompa, P., Szücs, K., Friedrich, P. \& Avila, J. Phosphorylation and dephosphorylation in the proline-rich C-terminal domain of microtubuleassociated protein 2. Eur. J. Biochem. 241, 765-771 (1996).

31. Cheng, S. Y., Wang, S. C., Lei, M., Wang, Z. \& Xiong, K. Regulatory role of calpain in neuronal death. Neural Regen. Res. 13, 556-562 (2018).

32. Juhaszova, M. et al. Glycogen synthase kinase-3beta mediates convergence of protection signaling to inhibit the mitochondrial permeability transition pore. J. Clin. Invest. 113, 1535-1549 (2004).

33. Mobasher, M. A. et al. Protein tyrosine phosphatase 1B modulates GSK3 B/Nrf2 and IGFIR signaling pathways in acetaminophen-induced hepatotoxicity. Cell Death Dis. 4, e626 (2013).

34. Rizvi, F. Shukla, S. \& Kakkar, P. Essential role of PH domain and leucine-rich repeat protein phosphatase 2 in Nrf2 suppression via modulation of Akt/ GSK3ß/Fyn kinase axis during oxidative hepatocellular toxicity. Cell Death Dis. 5, e1153 (2014).

35. Sunaga, D. et al. Accelerated recovery of mitochondrial membrane potential by GSK-3 $\beta$ inactivation affords cardiomyocytes protection from oxidantinduced necrosis. PLOS ONE 9, e112529 (2014).

36. Watanabe, N. \& Forman, H. J. Autoxidation of extracellular hydroquinones is a causative event for the cytotoxicity of menadione and DMNQ in A549-S cells. Arch. Biochem. Biophys. 411, 145-157 (2003).

37. Ding, Q. et al. Degradation of Mcl-1 by beta-TrCP mediates glycogen synthase kinase 3-induced tumor suppression and chemosensitization. Mol. Cell Biol. 27, 4006-4017 (2007)

38. Unterkircher, T. et al. Bortezomib primes glioblastoma, including glioblastoma stem cells, for TRAIL by increasing tBid stability and mitochondrial apoptosis. Clin. Cancer Res. 17, 4019-4030 (2011).

39. Henderson, C. J. et al. Caspase activation and apoptosis in response to proteasome inhibitors. Cell Death Differ. 12, 1240-1254 (2005).

40. Cross, D. A., Alessi, D. R., Cohen, P., Andjelkovich, M. \& Hemmings, B. A Inhibition of glycogen synthase kinase-3 by insulin mediated by protein kinase B. Nature 378, 785-789 (1995).

41. Frame, S., Cohen, P. \& Biondi, R. M. A common phosphate binding site explains the unique substrate specificity of GSK3 and its inactivation by phosphorylation. Mol. Cell 7, 1321-1327 (2001).

42. Alessi, D. R. \& Cohen, P. Mechanism of activation and function of protein kinase B. Curr. Opin. Genet. Dev. 8, 55-62 (1998).

43. Du, C., Fang, M., Li, Y., Li, L. \& Wang, X. Smac, a mitochondrial protein that promotes cytochrome c-dependent caspase activation by eliminating IAP inhibition. Cell 102, 33-42 (2000).

44. Bechard, M., Trost, R., Singh, A. M. \& Dalton, S. Frat is a phosphatidylinositol 3kinase/Akt-regulated determinant of glycogen synthase kinase $3 \beta$ subcellular localization in pluripotent cells. Mol. Cell Biol. 32, 288-296 (2012).

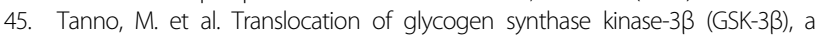
trigger of permeability transition, is kinase activity-dependent and mediated by interaction with voltage-dependent anion channel 2 (VDAC2). J. Biol. Chem. 289, 29285-29296 (2014).

46. Hüser, J. \& Blatter, L. A. Fluctuations in mitochondrial membrane potential caused by repetitive gating of the permeability transition pore. Biochem. $J$. 343, 311-317 (1999).

47. Watanabe, N., Dickinson, D. A., Liu, R. M. \& Forman, H. J. Quinones and glutathione metabolism. Methods Enzymol. 378, 319-340 (2004).

48. Deller, S., Macheroux, P. \& Sollner, S. Flavin-dependent quinone reductases. Cell Mol. Life Sci. 65, 141-160 (2008).

49. Bedard, K. \& Krause, K. H. The NOX family of ROS-generating NADPH oxidases: physiology and pathophysiology. Physiol. Rev. 87, 245-313 (2007).

50. Schmidlin, C. J., Dodson, M. B., Madhavan, L. \& Zhang, D. D. Redox regulation by NRF2 in aging and disease. Free Radic. Biol. Med. 134, 702-707 (2019). 
51. Asher, G., Lotem, J., Kama, R., Sachs, L. \& Shaul, Y. NQO1 stabilizes p53 through a distinct pathway. Proc. Natl Acad. Sci. USA 99, 3099-3104 (2002)

52. den Braver-Sewradj, S. P. Reduction and scavenging of chemically reactive drug metabolites by $\mathrm{NAD}(\mathrm{P}) \mathrm{H}:$ Quinone Oxidoreductase 1 and $\mathrm{NRH}$ :Quinone Oxidoreductase 2 and variability in hepatic concentrations. Chem. Res. Toxicol. 31, 116-126 (2018)

53. Kumagai, Y., Abiko, Y. \& Cong, N. L. Chemical toxicology of reactive species in the atmosphere: two decades of progress in an electron acceptor and an electrophile. J. Toxicol. Sci. 41, SP37-SP47 (2016).

54. Luanpitpong, $\mathrm{S}$. et al. Regulation of lung cancer cell migration and invasion by reactive oxygen species and caveolin-1. J. Biol. Chem. 285, 38832-38840 (2010).

55. Rada, P. et al. Structural and functional characterization of Nrf2 degradation by the glycogen synthase kinase 3/ß-TrCP axis. Mol. Cell Biol. 32, 3486-3499 (2012).

56. Gong, P. \& Cederbaum, A. I. Transcription factor Nrf2 protects HepG2 cells against CYP2E1 plus arachidonic acid-dependent toxicity. J. Biol. Chem. 281, 14573-14579 (2006).

57. Chen, $X$. et al. GSK-3 $\beta$ downregulates Nrf2 in cultured cortical neurons and in a rat model of cerebral ischemia-reperfusion. Sci. Rep. 6, 20196 (2016).

58. Xing, $H$. Y. et al. The cytoprotective effect of hyperoside against oxidative stress is mediated by the Nrf2-ARE signaling pathway through GSK-3 $\beta$ inactivation. PLOS ONE 10, e0145183 (2015).

59. Jiang, $Y$. et al. Therapeutic targeting of GSK3 $\beta$ enhances the Nrf2 antioxidant response and confers hepatic cytoprotection in hepatitis C. Gut 64, 168-179 (2015).

60. Mathur, A., Pandey, V. K. \& Kakkar, P. Activation of GSK3 $\beta / \beta-T r C P$ axis via PHLPP1 exacerbates Nrf2 degradation leading to impairment in cell survival pathway during diabetic nephropathy. Free Radic. Biol. Med. 120, 414-424 (2018).
61. Farr, S. A. et al. Antisense oligonucleotide against GSK-33 in brain of SAMP8 mice improves learning and memory and decreases oxidative stress: Involvement of transcription factor Nrf2 and implications for Alzheimer disease. Free Radic. Biol. Med. 67, 387-395 (2014).

62. Ranea-Robles, P. et al. Aberrant regulation of the GSK-3ß/NRF2 axis unveils a novel therapy for adrenoleukodystrophy. EMBO Mol. Med. 10, e8604 (2018).

63. Rojo, A. I. et al. Functional interference between glycogen synthase kinase-3 beta and the transcription factor Nrf2 in protection against kainate-induced hippocampal cell death. Mol. Cell Neurosci. 39, 125-132 (2008).

64. Meares, G. P. \& Jope, R. S. Resolution of the nuclear localization mechanism of glycogen synthase kinase-3: functional effects in apoptosis. J. Biol. Chem. 282 16989-17001 (2007)

65. Sgorbissa, A., Tomasella, A., Potu, H., Manini, I. \& Brancolini, C. Type I IFNs signaling and apoptosis resistance in glioblastoma cells. Apoptosis 16, 1229-1244 (2011)

66. Paroni, G. et al. Caspase-dependent regulation of histone deacetylase 4 nuclear-cytoplasmic shuttling promotes apoptosis. Mol. Biol. Cell 15, 2804-2818 (2004)

67. Paroni, G., Henderson, C., Schneider, C. \& Brancolini, C. Caspase-2-induced apoptosis is dependent on caspase-9, but its processing during UV- or tumor necrosis factor-dependent cell death requires caspase-3. J. Biol. Chem. 276, 21907-21915 (2001)

68. Di Giorgio, E. et al. The co-existence of transcriptional activator and transcriptional repressor MEF2 complexes influences tumor aggressiveness. PLoS Genet. 13, e1006752 (2017).

69. Diehl, J. A., Cheng, M., Roussel, M. F. \& Sherr, C. J. Glycogen synthase kinase3beta regulates cyclin D1 proteolysis and subcellular localization. Genes Dev. 12, 3499-3511 (1998) 